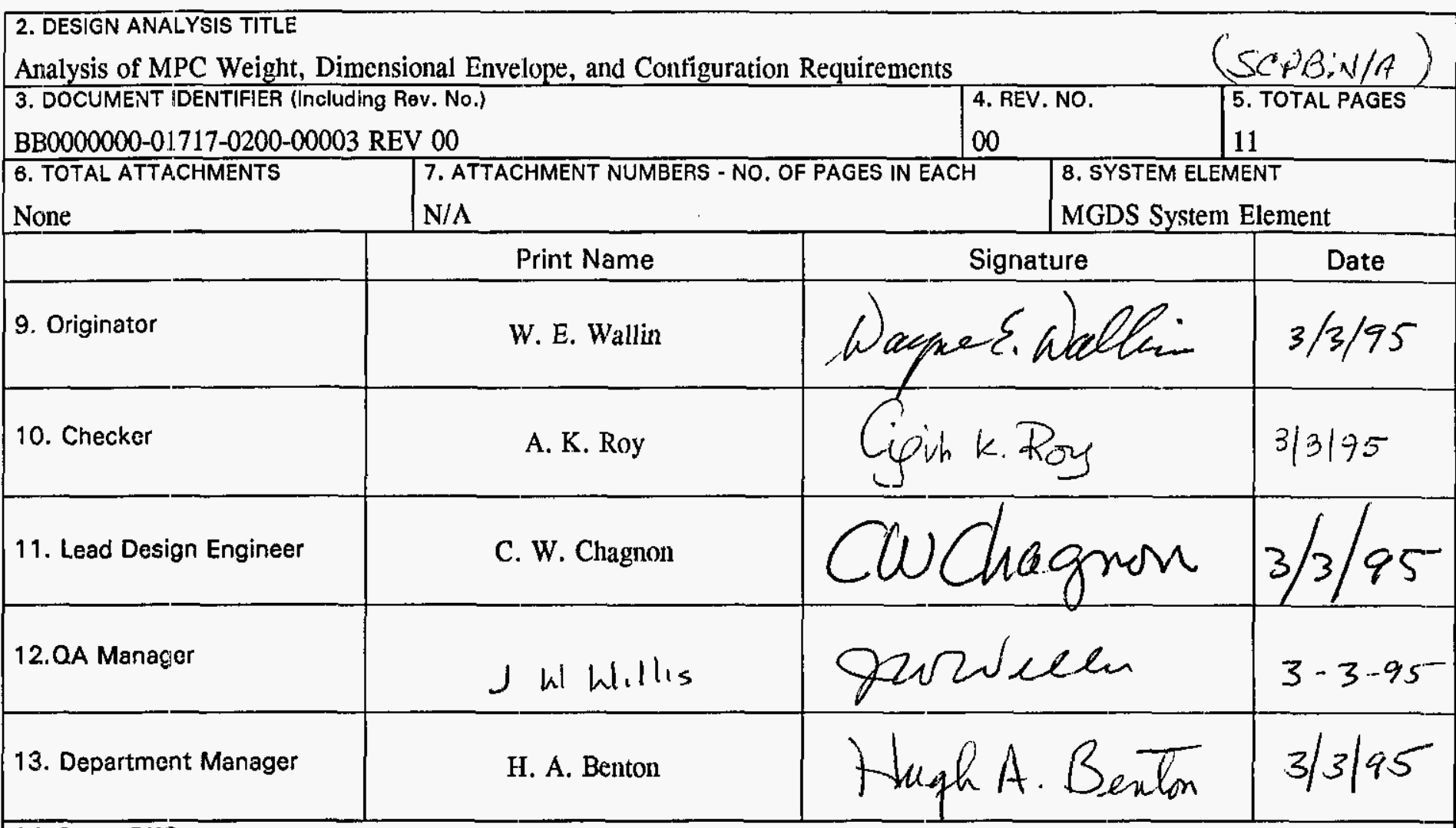

14. REMARKS 
9

CRWMS/M\&O

Design Analysis Revision Record

(1.) $\mid \begin{aligned} & \text { OA: } L \\ & \text { Page: } 2\end{aligned}$ Of: 11

2. DESIGN ANALYSIS TITLE

Analysis of MPC Weight, Dimensional Envelope, and Configuration Requirements

3. DOCUMENT IDENTIFIER (Including Rov. No.)

4. REVISION NO.

BB0000000-01.717-0200-00003 REV 00

00

5. Rovision No.

6. Total Pages

7. Description of Revision

00

11

Original Issue 


\section{ANALYSIS OF MPC WEIGHT, DIMENSIONAL ENVELOPE, AND CONFIGURATION REQUIREMENTS}


Title: Analysis of MPC Weight, Dimensional Envelope, and Configuration Requirements

Table of Contents:

$\underline{\text { Item }}$

Page

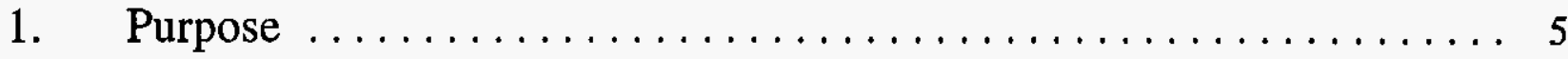

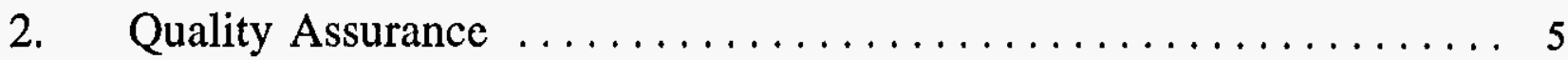

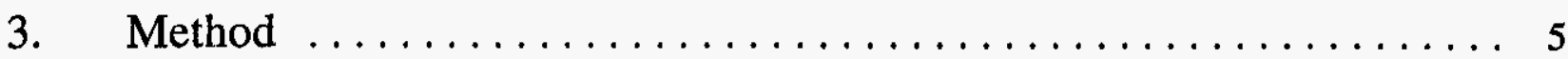

4. Design Inputs $\ldots \ldots \ldots \ldots \ldots \ldots \ldots \ldots \ldots \ldots \ldots \ldots \ldots$

4.1 Design Parameters $\ldots \ldots \ldots \ldots \ldots \ldots \ldots \ldots \ldots \ldots \ldots$

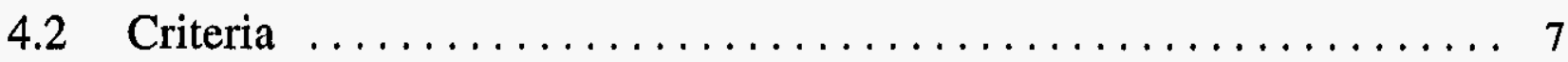

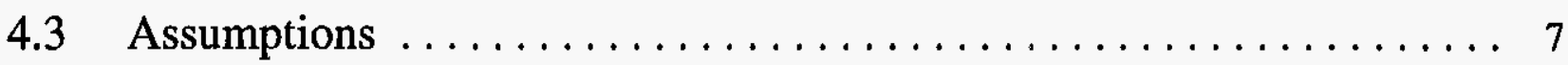

4.4 Codes and Standards $\ldots \ldots \ldots \ldots \ldots \ldots \ldots \ldots \ldots \ldots \ldots$

5. $\quad$ References $\ldots \ldots \ldots \ldots \ldots \ldots \ldots \ldots \ldots \ldots \ldots$

6. Use of Computer Software $\ldots \ldots \ldots \ldots \ldots \ldots \ldots \ldots \ldots$

7. Design Analysis $\ldots \ldots \ldots \ldots \ldots \ldots \ldots \ldots \ldots \ldots \ldots$

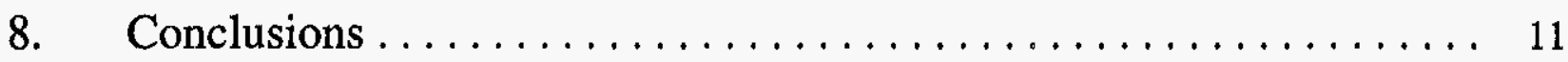

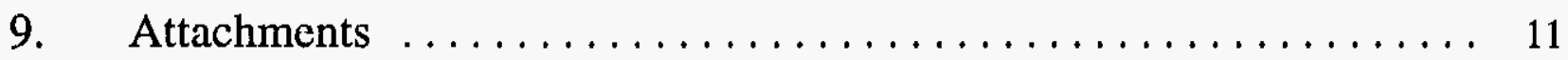


Title: Analysis of MPC Weight, Dimensional Envelope, and Configuration Requirements

\section{Purpose}

This analysis is prepared by the Mined Geologic Disposal System (MGDS) Waste Package Development Department (WPDD) in response to a request received via a QAP-3-12 Design Input Data Request ${ }^{(5.1)}$ from WAST Design (formerly MRS/MPC Design). The request is to provide:

1) Specific MPC weight, dimensional envelope, and configuration requirements to ensure compatibility with MGDS capabilities.

The objective of this analysis is to provide a response to the foregoing request. The purpose of this analysis is to provide the basis for the response. The response is stated in Section 8 herein.

\section{Quality Assurance}

The (QA Program applies to this analysis. This analysis focuses on compatibility of certain Multi-Purpose Canister (MPC) design features that interface with the MGDS. These features could potentially affect the proper functioning of the MGDS waste package; the waste package has been identified as an MGDS Q-List item that is important to radiological safety $^{(5.2)}$. A QAP-2-3 evaluation has not been performed for the MGDS wastc package (TBD-155). Preparation of this analysis is covered by section 2.4.7, MPC Design Compatibility with the MGDS, of the Evaluation of Waste Package Development Activities for Fiscal Year $1995^{(5.3)}$. This QAP-2-0 evaluation determined such activities to be subject to Quality Assurance Requirements and Description ${ }^{(5,4)}$ requirements.

\section{Method}

Information from the MPC Subsystem Design Procurement Specification ${ }^{(5.5)}$ and MPC Conceptual Design Report (CDR) ${ }^{(5.6)}$ were used as sources of MPC size and weight estimates; these estimates forming sizing inputs to MGDS waste packagc MPC disposal container conceptual designs. No design method or analytical model has been employed in this document. 
Title: Analysis of MPC Weight, Dimensional Envelope, and Configuration Requirements

\section{Design Inputs}

\subsection{Design Parameters}

Reference 5.6, Section 4.2.1, 125-Ton MPC:

length $=193.0$ in. $(4902 \mathrm{~mm})$, outside diameter $=60.30 \mathrm{in} .(1532 \mathrm{~mm})$ sealed MPC weight $=38$ ton $(34,500 \mathrm{~kg})$ for both 21 PWR MPC and 40 BWR MPC loaded transport cask (under hook, at spent fuel pool) with water $=106$ ton $(96,200$ $\mathrm{kg}$ ) for $21 \mathrm{PWR}$ MPC and $=105$ ton $(95,300 \mathrm{~kg}$ ) for $40 \mathrm{BWR}$ MPC

Note: all weights are without filler material.

Reference 5.6, Section 4.2.2, 75-Ton MPC:

length $=191.625 \mathrm{in} .(4867 \mathrm{~mm})$, outside diameter $=49.62 \mathrm{in} .(1260 \mathrm{~mm})$ sealed MPC weight $=25$ ton $(\sim 22,700 \mathrm{~kg})$ for 12 PWR MPC sealed MPC weight $=24$ ton $(21,800 \mathrm{~kg})$ for 24 BWR MPC Note: all wcights are without filler material.

Reference 5.5, Section 5.1.2.1, MPC Length:

Paragraph A. "MPC SAR design cavity lengths....shall accommodate the fuel lengths in Table 5.1.2.1-1 and Table 5.1.2.1-2." The largest value of fuel assembly length listed in those tables is 180.0 inches, and

Paragraph B. "MPC Alternative Designs shall consider only those cavity lengths specified in Table 5.1.1.2.2.1-1 and 5.1.1.2.2.2-1." The largest value of cavity length listed in those tables is 180 inches.

Reference 5.5, Section 5.1.2.2, Dimensional Interface:

Paragraph B. "The MPC assembly shall be a right circular cylinder with cylindricity..."

Reference 5.5, Section 5.1.2.3, Weight Limitations:

Paragraph A. "The maximum crane hook weight of the loaded cask systems....shall not exceed 125 tons for the series of the Large MPC configurations and 75 tons for the series of Small MPC configurations....", and 
Paragraph B. "The maximum crane hook weight of the loaded OST System....shall not exceed 100 tons for the series of the Large MPC configurations and 75 tons for the series of Small MPC configurations...."

\subsection{Criteria}

A. Waste package designs shall include disposal container designs for disposal of spent nuclear fucl contained within sealed MPCs as mandated by the following section and paragraphs of the MGDS Requirements Document (MGDS-RD) ${ }^{(5.7)}$ :

Section 3.1.5, Major Considerations and Assumptions

Paragraph J. "SNF will be received from the MRS and directly from Purchaser sites loaded in Transportation Cask Subsystems. Most, but not all, transportation cask subsystcms will incorporate a multi-purpose canister (MPC) with a transportation overpack....The MPC serves as a canister (basket) for the SNF for such purposes as confining the waste during transportation and storage and maintaining criticality control during transportation, storage, emplacement, and disposal...."

Paragraph $\mathrm{K}$, in part. "It is assumed that the MPC will remain sealed through the expected life cycle and will not be opened at the MGDS unless addition of filler material at the MGDS may be required as part of preparation for disposal."

Paragraph L. "The MGDS license will include the MPC for those waste package configurations that include an MPC."

B. The waste package design shall be dimensionally compatible with the MPC design as mandated by the following section and paragraph of the MGDS$\mathrm{RD}^{(5.7)}$ :

Section 3.2.3.2.3, MGDS-Transportation Interface Requirements

Paragraph $\mathrm{O}$, in part. "The waste package design shall be coordinated with the MPC design to ensure ... and dimensional compatibility."

C. Waste packagc costs shall be kept as low as reasonably achievable.

\subsection{Assumptions}

N/A (not applicable) 


\subsection{Codes and Standards}

ANSI Y14.5, Amcrican National Standard Enginecring Drawings and Related Documentation Practices, Dimensioning and Tolerancing, 1982, reaffirmed 1988.

\section{References}

5.1 QAP-3-12 Design Input Data Request, N. L. Seagle, 11/13/93, to W. D. Schutt, an attachment to IOC CH.MRS.NLS.11/93.081, Stringer to Schutt, November 16,1993

5.2 Yucca Mountain Site Characterization Project Q-List, YMP/90-55Q, REV 3, December 1994

5.3 Evaluation of Waste Package Development Activities for Fiscal Year 1995, DI\# BBA000000-01717-2200-00003 REV 00, December 6, 1994

5.4 Quality Assurance Requirements and Description, DOE/RW-0333P, Rev. 1, July 21, 1994

5.5 Multi-Purpose Canister (MPC) Subsystem Design Procurement Specification, DI\# DBG000000-01717-6300-00001 REV 04, August 26, 1994

5.6 Multi-Purpose Canister (MPC) Implementation Program Conceptual Design Phase Report, Volume II.A - MPC Conceptual Design Report, DI\# A2000000000811-5705-00002 REV 00, September 1994

5.7 Mined Geologic Disposal System Requirements Document, DI\# B0000000000811-1708-00002 REV 01, March 1994

\section{Use of Computer Software}

N/A 
Title: Analysis of MPC Weight, Dimensional Envelope, and Configuration Requirements

\section{Design Analysis}

MPC maximum size and weight are gencrally established and constrained by the specifications for the Large MPC series, as contained within the MPC Subsystem Design Procurement Specification (DPS) ${ }^{(5.5)}$; Section 5.1.2, Physical Characteristics. Nominal values for Large MPC and Small MPC series conceptual designs are as listed in Section 4.1 herein.

The large MPC series weights are indicated as 38 tons, from the MPC $\mathrm{CDR}^{(5.6)}$, Section 4.2.1, 125-Ton MPC. Crane hook weight limitation will limit the weight allocation available to the Large MPC series to be generally less than 45 tons (by ratio of: 38 tons per MPC CDR * 125 tons crane limit / 106 tons under hook per CDR design). Thus, in the final production design configuration, slightly larger Large MPC series sizes may possibly be considered (such as 24 PWR size compared to the 21 PWR size for CDR design) and yet stay within the MPC Subsystem DPS weight constraints indicated above.

The MPC Subsystem DPS Section 5.1.2.1, MPC Length, specifies a cavity length of 180 inches (4572 mm). The MPC CDR Section 4.2.1, 125-Ton MPC, establishes the Large MPC series overall right-cylinder length as 193 inches $(4902 \mathrm{~mm})$. Thus, overall length of the MPC conceptual designs as well as production designs, even considering the possibility of a thicker radiation shicld, may be established as being approximately $5000 \mathrm{~mm}$ or less.

The MPC CDR Section 4.2.1, 125-Ton MPC, establishes outside diameter as 60.3 inches (1532. $\mathrm{mm}$ ) for the Large MPC series. Given the foregoing Large MPC series limitations as to weight and thus, number of fuel assemblies, the resulting maximum outside diameter for the Large MPC series may be expected to lie in the range of 60 to 65 inches (1524 to 1651 $\mathrm{mm}$ ).

MGDS requirements are derived from the Mined Geologic Disposal System Requirements Document (MGDS-RD ${ }^{(5.7)}$ ), which embraces the MPC as an integral feature of the Civilian Radioactive Waste Management System. The MPC was incorporated into the MGDS-RD as a design feature of disposal in fiscal year 1994. Since then, all MGDS repository and waste package design and analysis activities have been completely responsive to incorporation of the MPC as a major feature of disposal design.

Approximate values for maximum sizes and weights have been presented in the preceding paragraphs for the Large MPC series, as derived from requirements in the MPC Subsystem DPS and information in the MPC CDR. The Small MPC scries are approximately the same length as the Large MPC scrics, only smaller in diameter $(1260 \mathrm{~mm}$ versus $1532 \mathrm{~mm}$ ) and containing fower fucl assemblies (for example, 12 versus 21 for the PWR case). Sizes and weights for both the Large MPC series and Small MPC series neither suggest nor require imposition of any additional limitations upon loaded MPC weight or nominal envelope except as stated herein; the MGDS will design the MPC disposal containers to accommodate sealed 
Title: Analysis of MPC Weight, Dimensional Envclope, and Configuration Requirements

waste-containing MPCs which have been produced in accordance with the final production MPC Subsystem DPS.

MPC disposal container conceptual designs, for both the Large MPC series and Small MPC series, are each internally configured as a right circular cylinder into which the MPC is to be placed. Also, the MPC $\mathrm{CDR}^{(5.6)}$ shows the MPC shell as a right circular cylinder having no exterior protrusions. The MGDS MPC disposal container design is based on and relies upon the MPC concept showing no protrusions from the sides of the MPC, including: grappling and handling features, and/or MPC unique identification label.

Should future MPC designs allow protrusions from the sides, then the MPC disposal container designs would have to be modified accordingly to accommodate this MPC feature. This would increase the cost of the disposal container and is further justification for not allowing protrusions. Such a circumstance would impose an additional requirement upon MGDS, that being proper angular orientation of the MPC as it is placed into a disposal container; an unnecessary requirement when dealing with right circular cylinders.

The MPC disposal container design will allow for a small gap between the MPC and disposal container inner surface, as necessary to accommodate for cylindricity tolerancing of both the MPC and the disposal container. In order to establish consistency in dimensioning and tolerancing between the MPC Subsystem and the MGDS, the latest applicable revision of ANSI Y14.5 must be applied to all design and detail drawings. 
Title: Analysis of MPC Weight, Dimensional Envelope, and Configuration Requirements

\section{Conclusions}

The MGDS response to request \#1, as stated in Section 1, is as follows:

In recognition of the general limitations upon MPC sizes and weights as established by the MPC Subsystem DPS constraints, the MGDS does not require imposition of any additional limitations upon loaded MPC weight or nominal envelope except as stated herein; the MGDS will design the MPC disposal containers to accommodate sealed waste-containing MPCs which have been produced in accordance with the final production MPC Design Procurement Specification.

There shall be no protrusions from the sides of the MPC, including: grappling and handling features, and/or MPC unique identification label.

The latest applicable revision of ANSI Y14.5 must be applied to all design and detail drawings.

\section{Attachments}

\section{N/A}

